\title{
An analysis of patient register data in the Longitudinal Study - what does it tell us about the quality of the data?
}

Steve Smallwood and Kevin Lynch

Office for National Statistics

\begin{abstract}
This article uses data for members of the ONS Longitudinal Study (LS) from both Census 2001 enumeration and patient registrations "frozen" on census day 2001 from the National Health Service Central Register (NHSCR) to examine potential sources of difference in area of usual residence.
\end{abstract}

Overall 95.7 per cent of ONS LS members enumerated at census resided in the same area as recorded on the NHSCR data. Where areas differed, or the ONS LS member was not on the NHSCR on census day, subsequent NHSCR records were examined. Records flagged on the NHSCR as ONS LS members in England and Wales on census day but with no census record were also investigated. 


\section{Contents}

An analyssis of patient register data in the Longitudinal Study - what does it tell us about the quality of the data?

Abstract 151

Introduction 153

The ONS Longitudinal Study 153

The approach 153

Discussion 167

Conclusion 167

Acknowledgement. 168

References 169 


\section{Introduction}

Patient register information is a key administrative source used in the construction of population estimates $^{1}$. It is also used in the construction of small area population figures ${ }^{2}$. The main use of this information is for estimating internal migration between local authorities. Previous work has considered aggregate (macro) level comparisons of patient register and census data ${ }^{3}$. However a systematic analysis of linked (micro level) data analysis has not been carried out. The micro comparisons here help in understanding the quality of the information used and may provide lessons for rebasing the mid-year estimates after the 2011 Census. Increasingly, however, administrative sources are being considered for use in constructing demographic information. The Department of Health are also considering making increased use of the information they hold for resource allocation; they therefore have an interest in the quality of the patient register information. This article uses the one data source that links information from patient registration to census data, the ONS Longitudinal Study.

\section{The ONS Longitudinal Study}

The ONS Longitudinal Study (LS) contains linked census and vital event data for one per cent of the population, selected using dates of birth, for England and Wales. Information from the 1971, 1981, 1991 and 2001 Censuses has been linked together, along with information on events such as births, deaths and cancer registrations. At each census, data on more than 500,000 sample members are included. During the 30 years of the study, over one million people have been recorded in the sample at some point. ${ }^{4}$

The ONS LS was set up in the 1970s to meet the need for better data on mortality and fertility. Since then it has been used to address a wide range of research questions including studies of social mobility, ageing and migration. Information on migration comes from patient registration data on the National Health Service Central Register (NHSCR) ${ }^{5}$ accessed using the Central Health Register Inquiry System (CHRIS). The paper uses some terms which relate to the data on the NHSCR which may not be familiar to readers; these are described in Box one.

\section{The approach}

The comparison of 2001 Census data with information on patient registration from the NHSCR provides a unique opportunity to see where the census placed people in the population compared with the patient register data. The ONS LS now has NHSCR data up to 2007 and so it is possible to get a good picture of how the census compares with the GP register data and subsequent changes through the decade. There are, however, some limitations to the analysis in that moves on the NHSCR are only picked up between Health Authorities (HAs), the former health areas before the introduction of Primary Care Organisations in $2001^{6}$. It should be noted that this comparison is between the health area where people were actually resident, based on census enumeration address, with the area in which they were registered with a GP. For sub-national migrants the population estimates will contain similar time lags and 'errors' as the NHSCR and other NHS systems giving GP registration data, as sub-national migration moves are derived from those data sets. 


\section{Box one}

\section{Terminology used for National Health Service Central Register data}

\section{Posting}

This term refers to the move of a patient's registration from one health authority area to another.

\section{Cancellation}

This refers to the removal of a patient from the NHSCR - this will normally be because a General Practitioner has notified that the person has left their practice and can no longer be traced.

\section{Embarkation}

This refers to patient records where the patient has notified the doctor that they are moving abroad. Technically anyone who goes abroad for more than three months should notify their doctor.

Moves between health authority areas clearly do not cover all moves, but they do cover around four in five moves between local authorities. Examining the moves in the ONS LS Census data in the year prior to 2001 Census (using the address one year ago question) 78.5 per cent of moves across local authority boundaries were also moves between health authority areas. This compares with a very similar figure of 79.4 per cent for moves in the period mid-2000 to mid-2001 from the data used to create internal migration moves for mid-year estimates. Note that there will be a small number of cases in the analysis in this paper where NHSCR picks up where the patient registers with a doctor in a different health authority area but the move was within a local authority area.

Information on five different groups of people was examined. These groups were:

\section{(1) Those present at 2001 Census $^{7}$ who also have an NHSCR record for the same area current at the 2001 Census date}

For this group we can assume that the census, and therefore mid-year population estimates (MYEs) based on the census, have the person in the correct place. Although place here refers to health authority area, it does not necessarily mean people are recorded at the same address as the LS does not hold NHSCR address data. Note that it is also possible for individuals to be at the same home address on both the census and the GP register, but the GP surgery may be across a health area boundary.

\section{(2) Those present at 2001 Census but whose NHSCR record at census day in 2001 is in an} area other than their Census address

For this group it seems reasonable to assume that the census has the person in the correct place but that the GP register does not, as Census is completed at a particular point in time. Of course, if these people subsequently move internally on the NHSCR then the MYEs may wrongly move 
those people into an area where they have already been placed by the census (taking them out of an area in which they were not enumerated).

(3) Those present at 2001 Census but whose NHSCR record had been cancelled prior to census day and no active record exists at 2001

For this group it can be assumed that the person is missing from the NHSCR, either because they have been 'wrongly' removed, correctly removed but failed to re-register, or that they are legitimately not on the register as they are covered by other medical arrangements, for example, that they are in the armed forces.

\section{(4) Those present at 2001 Census but not appearing until later on the NHSCR, if ever}

This group is likely to consist of migrants who have not registered with the NHS at the time of the census and who may or may not register later.

\section{(5) Those absent at 2001 Census for whom an NHSCR record existed at census time}

Many of this group will be census 'non response' or will be LS members who have replied to census but the information could not be linked; however, it will also include those who have left England and Wales ${ }^{8}$ but not notified their GP that they have left.

In order to get an idea of the importance of each of these groups they need to be seen in the context of the total population. For categories 1 to 4 above the total denominator is the number of ONS LS members found in the 2001 Census. For category (5) the denominator is considered to be the total number of people found on the NHSCR at 2001 using the selection criteria for the ONS

LS. Table 1 shows the numbers found in each of the five groups.

\section{Table 1 Categories examined, sample sizes and percentage of total*}

\begin{tabular}{lcc}
\hline Category & $\begin{array}{c}\text { Numbers } \\
\text { found }\end{array}$ & $\begin{array}{c}\text { Per cent } \\
\text { of total }\end{array}$ \\
\hline
\end{tabular}

(1) Those present at 2001 Census $^{6}$ who also have an NHSCR record for the same area $\quad 516,758$ 95.7 current at the 2001 Census date

(2) Those present at 2001 Census $^{6}$ but whose NHSCR record at census day in 2001 is in $\quad 14,806$ an area other than their census address

(3) Those present at 2001 Census $^{6}$,but whose NHSCR record had been cancelled prior to census day and no active record exists at 2001 3(a) Non armed forces 3(b) Armed forces

$4,434 \quad 0.8$

$3,155 \quad 0.6$

$1,279 \quad 0.2$

(4) Those present at 2001 Census $^{6}$ but not appearing until later on the NHSCR, if ever.

3,867

(5) Those 'absent' at 2001 Census $^{6}$ for whom an NHSCR record existed at census time* 88,961 14.9

\footnotetext{
* Note that the denominator for categories (1) to (4) is the total number of people found in the Longitudinal Study 2001 Census sample. The denominator for category (5) is the total number of people selected from the NHSCR using the selection criteria for the Longitudinal Study.
}

So, at the 2001 Census, over 95 per cent of people in the Longitudinal Study were resident in the same Health Authority area on the NHSCR as their address given in their census return. Of the 
remainder, the majority were in a different Health Authority area (2.8 per cent), while 1.5 per cent were not on the NHSCR, with around half of these having never appeared there.

Category 5 is a particularly interesting group, but is quite difficult to interpret, as there are a number of reasons why there may be a GP record but no census record. These will include underenumeration in the census and linkage issues in the LS, as well as those who have remained on the patient register but have left the country. Table 2 gives a brief summary of what the data can tell us about this group.

Members can enter the ONS LS in three ways, through being found in a census, by being identified as an inward migrant into England and Wales in the NHSCR or through birth registration. Table 2 combines entry via census and from the NHSCR, but splits that category between whether the LS members were born in England and Wales or outside (migrants). Those that have entered through birth alone are then shown separately.

\section{Table 2 Subsequent actions on NHSCR for those on register, but no census enumeration or census link, 2001-2006}

\begin{tabular}{lrrrr|rr|rr}
\hline & \multicolumn{2}{c}{ Entered ONS LS via census / NHSCR } & \multicolumn{2}{c|}{ Entered ONS LS } & \multicolumn{2}{c}{ Total } \\
\cline { 2 - 8 } & E\&W born & $\begin{array}{r}\text { Per } \\
\text { cent }\end{array}$ & Migrant & $\begin{array}{r}\text { Per } \\
\text { cent }\end{array}$ & $\begin{array}{r}\text { via E\&W } \\
\text { birth }\end{array}$ & $\begin{array}{r}\text { Per } \\
\text { cent }\end{array}$ & $\begin{array}{r}\text { Number } \\
\text { Per } \\
\text { cent }\end{array}$ \\
\hline No postings & 20,282 & 63 & 12,889 & 44 & 17,156 & 63 & 50,327 & 57 \\
Movement to: & & & & & & & \\
$\quad$ England or Wales & 4,141 & 13 & 3,302 & 11 & 5,780 & 21 & 13,223 & 15 \\
$\quad$ Scotland or Northern Ireland & 186 & 1 & 177 & 1 & 163 & 1 & 526 & 1 \\
Death & 2,281 & 7 & 146 & 1 & 77 & 0 & 2,504 & 3 \\
Cancelled & 4,026 & 12 & 11,020 & 38 & 2,314 & 8 & 17,360 & 20 \\
Armed Forces & 27 & 0 & 8 & 0 & 100 & 0 & 135 & 0 \\
Embarked & 577 & 2 & 955 & 3 & 302 & 1 & 1,834 & 2 \\
Live birth & 400 & 1 & 629 & 2 & 1,421 & 5 & 2,450 & 3 \\
Cancer registration & 481 & 1 & 63 & 0 & 58 & 0 & 602 \\
Total & $\mathbf{3 2 , 4 0 1}$ & & $\mathbf{2 9 , 1 8 9}$ & & $\mathbf{2 7 , 3 7 1}$ & $\mathbf{8 8 , 9 6 1}$ \\
\hline
\end{tabular}

Nearly three fifths (57 per cent) of those found on the NHSCR but with no census form remain on the register with no further evidence of any activity. As stated previously, these people may have not responded to the 2001 Census, or there was an issue with linking their record to census data. It is also possible they may have left the country and not told their GP surgery (although list checking and cleaning should have identified this). One fifth were cancelled or embarked. Although the cancellation is after the census it is possible that some may have left before the census. The remaining fifth had activity which definitely indicated presence at some point after 2001. Patterns are broadly similar across the three groups of entry into the ONS LS identified in Table 2. However, the migrant group has a lower proportion with no activity and a higher proportion of cancellations. Further information on non-linkage and patient register data can be found in an article produced after the 2001 Census link ${ }^{9}$. The remainder of this article concentrates on those groups where we have census information, allowing a direct comparison between place at time of the 2001 Census and subsequent changes in NHS registration information captured by the ONS LS (categories (2) to(4) above). 
Those present at 2001 Census but whose NHSCR record on 2001Census day is in an area other than their census address (category 2): what happened next?

Table 3 shows what subsequently happened to those who were at a different place on the NHSCR compared with census. The table shows that after six years over one half of this group did not end up being moved into the area in which the census found them. Of those, around one half had no other posting on the NHSCR.

\section{Table 3 Next NHSCR event for those found in a different HA on NHSCR compared with the 2001 Census}

\begin{tabular}{lrr}
\hline & Number & Per cent \\
\hline Moves them into their 2001 Census area & 6,896 & 46.6 \\
Moves them into another area & 2,239 & 15.1 \\
Shows an embarkation & 42 & 0.3 \\
Shows a cancellation & 1,429 & 9.7 \\
Died & 142 & 1.0 \\
Enlisted in the armed forces & 76 & 0.5 \\
Other & 78 & 0.5 \\
No post 2001 Census posting & 3,904 & 26.4 \\
TOTAL & & \\
\hline
\end{tabular}

The cases identified in the first row of Table 3 are a gross difference; however, it is quite possible that such differences may produce little net effect if, for example, for every person who is wrongly recorded on the patient register in Newcastle and recorded on the census in London there is a similar person (by age and sex) recorded on a patient register in London but recorded on the census in Newcastle.

Sample numbers are too small to examine this by individual health authority area, instead we have examined where the differences are by Government Office Region (GOR). Of the records examined just over half (51 per cent) were in the same GOR. Figure 1 shows the gross numbers in a different GOR and the net numbers once cancelling has taken place to allow for compensating errors. Figure 1 shows that gross differences are concentrated in London and the South East, areas with large populations and with high levels of internal migration. Reassuringly, once gross differences are 'netted off' they become much smaller, although there is a clear geographical pattern with the East of England, South East and South West having net positive differences (that is there are slightly fewer people on the NHSCR in other regions who should be in those regions than there are people in the East of England, South East and South West regions who should be elsewhere), while more northern areas have net negative differences (that is there are slightly more people on the NHSCR in other regions who should be in those regions than there are people in those northern regions who should be elsewhere). It is particularly noteworthy that London and the South East have very small net differences despite having the largest gross differences. Of course, if there are very different effects at sub-GOR geography, then differences in the age-sex characteristics of the movers involved, or different time lags in subsequent moves between different areas, then these may still lead to quality issues. Although the sample numbers are too small to consider the timing of these moves between individual GORs, the overall average length of time for moves into and out of GORs can be calculated and are shown in Table 4. Note that this only refers to the average length (in months) of moves that have occurred by around six years after 
the 2001 Census; the figures are, therefore, censored in that they don't include those who take more than six years to move.

\section{Figure 1 Gross and net numbers where NHSCR has different GOR from census area, and patients subsequently move to census area}

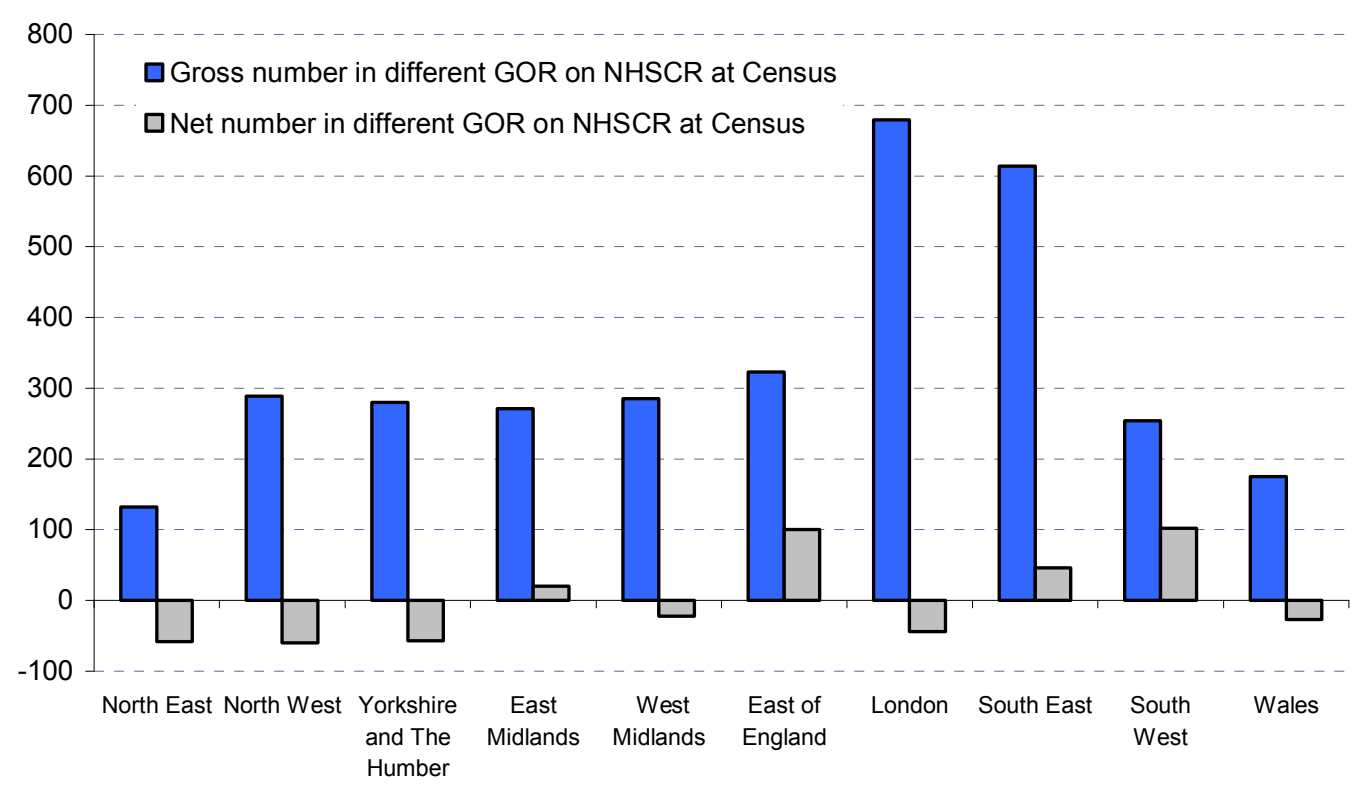

\section{Table 4 Months taken to move from GOR on NHSCR to GOR in census for those who moved between the 2001 Census and the end of 2006}

\begin{tabular}{lccc}
\hline Government Office Region & $\begin{array}{c}\text { Per cent moving } \\
\text { from GOR }\end{array}$ & $\begin{array}{c}\text { Per cent moving } \\
\text { to GOR }\end{array}$ & Difference \\
\hline North East & 12.0 & 9.2 & +2.8 \\
North West & 13.9 & 12.2 & +1.7 \\
Yorkshire and The Humber & 13.5 & 13.3 & +0.3 \\
East Midlands & 14.1 & 12.0 & +2.0 \\
West Midlands & 13.9 & 12.9 & +1.1 \\
East of England & 12.5 & 14.1 & -1.6 \\
London & 14.1 & 15.4 & -1.3 \\
South East & 13.4 & 13.3 & +0.2 \\
South West & 12.6 & 13.3 & -0.7 \\
Wales & 13.2 & 13.4 & -0.2 \\
Total & $\mathbf{1 3 . 5}$ & $\mathbf{1 3 . 5}$ & - \\
\hline
\end{tabular}

In general there are not large differences in time between moves into and out of an area. It is noticeable that it takes longer for people to be moved into London, the East of England, the South West and Wales than it takes for them to be moved out of those areas. This may relate to the type of people (younger, less likely to approach their GP), or it may relate to administrative differences. However these are averages, which are also censored, and ideally distributions would also need to be examined to draw any strong conclusions. 
Those present at 2001 Census but whose NHSCR record had been cancelled prior to Census day and no active record exists at 2001 (category 3): what happened next?

Table 5 shows what subsequently happened to those who were cancelled on the NHSCR prior to census but who appeared in the 2001 Census.

\section{Table 5 Next NHSCR event for those found in 2001 Census but with no active GP record}

\begin{tabular}{|c|c|c|c|}
\hline & & Number & $\begin{array}{l}\text { Per cent } \\
\text { of total }\end{array}$ \\
\hline \multicolumn{4}{|c|}{ All in Category } \\
\hline \multicolumn{2}{|c|}{ Registration puts them into their 2001 Census area } & 1,829 & 41.3 \\
\hline \multicolumn{2}{|c|}{ Registration puts them into another area } & 768 & 17.3 \\
\hline \multicolumn{2}{|c|}{ Died } & 49 & 1.1 \\
\hline \multicolumn{2}{|c|}{ Enlisted in the armed forces } & 9 & 0.2 \\
\hline \multicolumn{4}{|c|}{ Shows an embarkation 7} \\
\hline \multicolumn{4}{|c|}{ Shows a cancellation } \\
\hline \multirow{2}{*}{\multicolumn{2}{|c|}{$\begin{array}{l}\text { Other } \\
\text { No post } 2001 \text { Census posting }\end{array}$}} & & 2.1 \\
\hline & & 1,687 & 38.0 \\
\hline \multicolumn{2}{|c|}{ TOTAL } & 4,434 & 100 \\
\hline \multicolumn{4}{|c|}{ Of which: (a) Non Armed forces } \\
\hline \multirow{3}{*}{\multicolumn{2}{|c|}{$\begin{array}{l}\text { Moves them into their } 2001 \text { Census area } \\
\text { Moves them into another area } \\
\text { Died }\end{array}$}} & 1,511 & 47.9 \\
\hline & & 489 & 15.5 \\
\hline & & 46 & 1.5 \\
\hline \multicolumn{4}{|c|}{ Enlisted in the armed forces } \\
\hline \multicolumn{4}{|c|}{ Shows an embarkation } \\
\hline \multicolumn{4}{|c|}{ Shows a cancellation } \\
\hline \multirow[t]{2}{*}{ Other } & & 30 & 1.0 \\
\hline & No post 2001 Census posting & 1,079 & 34.2 \\
\hline TO & TAL & 3,155 & 100 \\
\hline \multirow[t]{3}{*}{ (b } & ) Armed Forces & & \\
\hline & Moves them into their 2001 Census area & 318 & 24.9 \\
\hline & Moves them into another area & 279 & 21.8 \\
\hline \multirow[t]{6}{*}{ Died } & & 3 & 0.2 \\
\hline & Enlisted in the armed forces & & \\
\hline & Shows an embarkation & & \\
\hline & Shows a cancellation & & \\
\hline & Other & 71 & 5.5 \\
\hline & No post 2001 Census posting & 608 & 47.5 \\
\hline TO & TAL & 1,279 & 100 \\
\hline
\end{tabular}

* Categories have been collapsed for disclosure control

Around 41 per cent of these people reappear in the area in which the 2001 Census found them, although this increases to 48 per cent when excluding the armed forces. There were 38 per cent who had not reappeared over six years after census, although this reduces to 34 per cent when armed forces are removed. As these are people who have previously been selected as LS members and have been found in the census it might seem odd that they have not reappeared on the NHSCR six years later. There are also 17 per cent of this group who turn up in another area, the proportion being slightly lower for non-armed forces and understandably slightly higher for armed forces. 
Those present at 2001 Census but not appearing until later on the NHSCR, if ever (Category 4): what happened next?

Table 6 shows those who had never been on the NHSCR at the time of the 2001 Census and what subsequently happened to them.

\section{Table 6 Next NHSCR event for those found in 2001 Census, but with no previous GP record}

\begin{tabular}{|c|c|c|}
\hline Event & Number & $\begin{array}{r}\text { Per cent } \\
\text { of total }\end{array}$ \\
\hline Moves them into their 2001 Census area & 954 & 24.7 \\
\hline Moves them into another area & 294 & 7.6 \\
\hline Died & 25 & 0.6 \\
\hline Enlisted in the armed forces & 0 & 0.0 \\
\hline \multicolumn{3}{|l|}{ Shows an embarkation } \\
\hline \multicolumn{3}{|l|}{ Shows a cancellation } \\
\hline Other & 11 & 0.3 \\
\hline No post 2001 Census posting & 2,583 & 66.7 \\
\hline TOTAL & 3,867 & 100 \\
\hline
\end{tabular}

* Categories have been collapsed for disclosure control

Around one quarter of those who are found in the census and have no previous GP record turn up in the area in which they were found in the 2001 Census. Two-thirds did not appear on the NHSCR in the six years following the census - this is equivalent to around 0.5 per cent of all linked records. Most of the remaining people in this category turn up in another area.

\section{More detailed analysis by age and sex}

It is possible to 'drill down' into the data provided to look at age/sex distributions and other characteristics from the census, for example student status. A limited amount of work has been carried out on this with the following tentative findings.

Table 7 demonstrates that there is a strong male bias for most of those who are either in a different place, are not on the NHSCR, or are on the register but absent from the 2001 Census. Given that there is evidence that census missed enumerating more young men than women, it suggests this may be a conservative estimate of the sex bias for those that are in the census ${ }^{10}$. The bias is likely to reflect well known issues of male engagement with GP services being both later and lower than for females.

Figure 2 shows the age patterns for the different groups for those present at 2001 Census.

Before considering the results in Figure 2 it should be remembered that by far the largest group is those for whom the 2001 Census and the NHSCR show the same place (see Table 1). It is clear however that all the other categories have a very much younger age distribution compared with that very large group.

The age distributions for those where the 2001 Census and the NHSCR disagree about the address, or where there is no NHSCR record prior to census, are very similar. Those where 
NHSCR has been cancelled pre census, while still a younger distribution, is less peaked at younger ages, with a noticeably higher proportion of people in the 40-59 age group.

\section{Table 7 Number of cases by sex and sex ratios of categories examined}

\begin{tabular}{|c|c|c|c|}
\hline Category & Men & Women & $\begin{array}{l}\text { Sex ratio: men } \\
\text { per } 100 \text { women }\end{array}$ \\
\hline $\begin{array}{l}\text { (1) Those present at } 2001 \text { Census who also have an NHSCR } \\
\text { record for the same area current at the } 2001 \text { Census date }\end{array}$ & 247,135 & 269,623 & 91.7 \\
\hline $\begin{array}{l}\text { (2) Those present at } 2001 \text { Census but whose NHSCR record on } \\
\text { census day in } 2001 \text { is in an area other than their census address }\end{array}$ & 9,015 & 5,791 & 155.7 \\
\hline $\begin{array}{l}\text { ( } 3 \text { ) Those present at } 2001 \text { Census but whose NHSCR record } \\
\text { had been cancelled prior to census day and no active record } \\
\text { exists at } 2001\end{array}$ & 2,765 & 1,669 & 165.6 \\
\hline 3(a) Non Armed forces & 1,713 & 1,442 & 118.8 \\
\hline 3(b) Armed forces & 1,052 & 227 & 463.4 \\
\hline $\begin{array}{l}\text { (4) Those present at } 2001 \text { Census but not appearing until later } \\
\text { on the NHSCR, if ever. }\end{array}$ & 2,346 & 1,521 & 154.2 \\
\hline $\begin{array}{l}\text { (5) Those' absent' at } 2001 \text { Census for whom an NHSCR record } \\
\text { existed at census time }\end{array}$ & 51,570 & 37,391 & 137.9 \\
\hline
\end{tabular}

\section{Figure 2 Age distribution of different categories of those present at the 2001 Census}

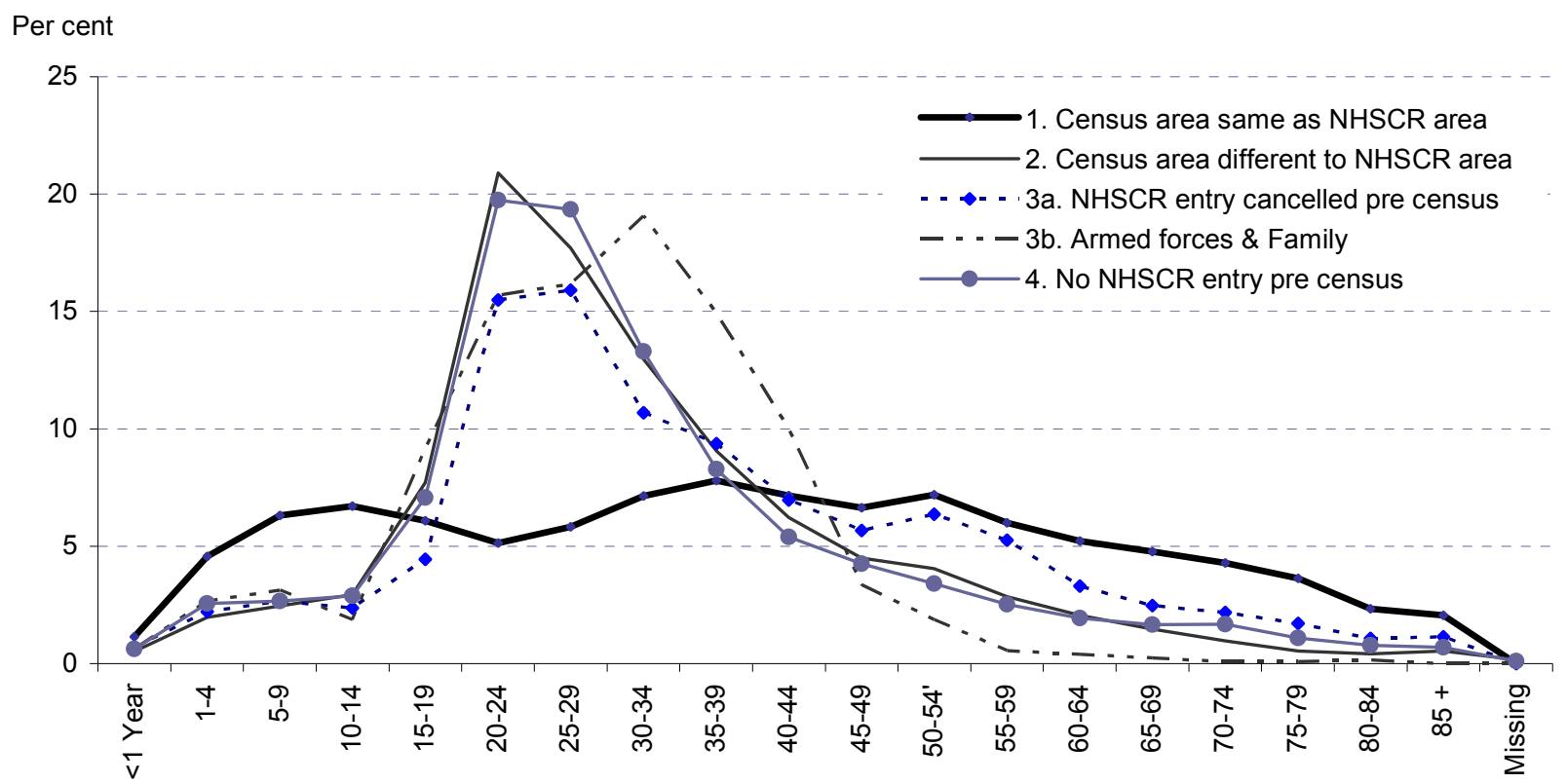


Figure 3 shows the data in Figure 2 separately for males and females. The patterns for males and females are very similar, although the female 'NHSCR entry cancelled pre-census' group has a distribution even closer to the overall population distribution than the male distribution.

\section{Figure 3 Age distribution of different categories of those present at 2001 Census, male and female}

(a) Males

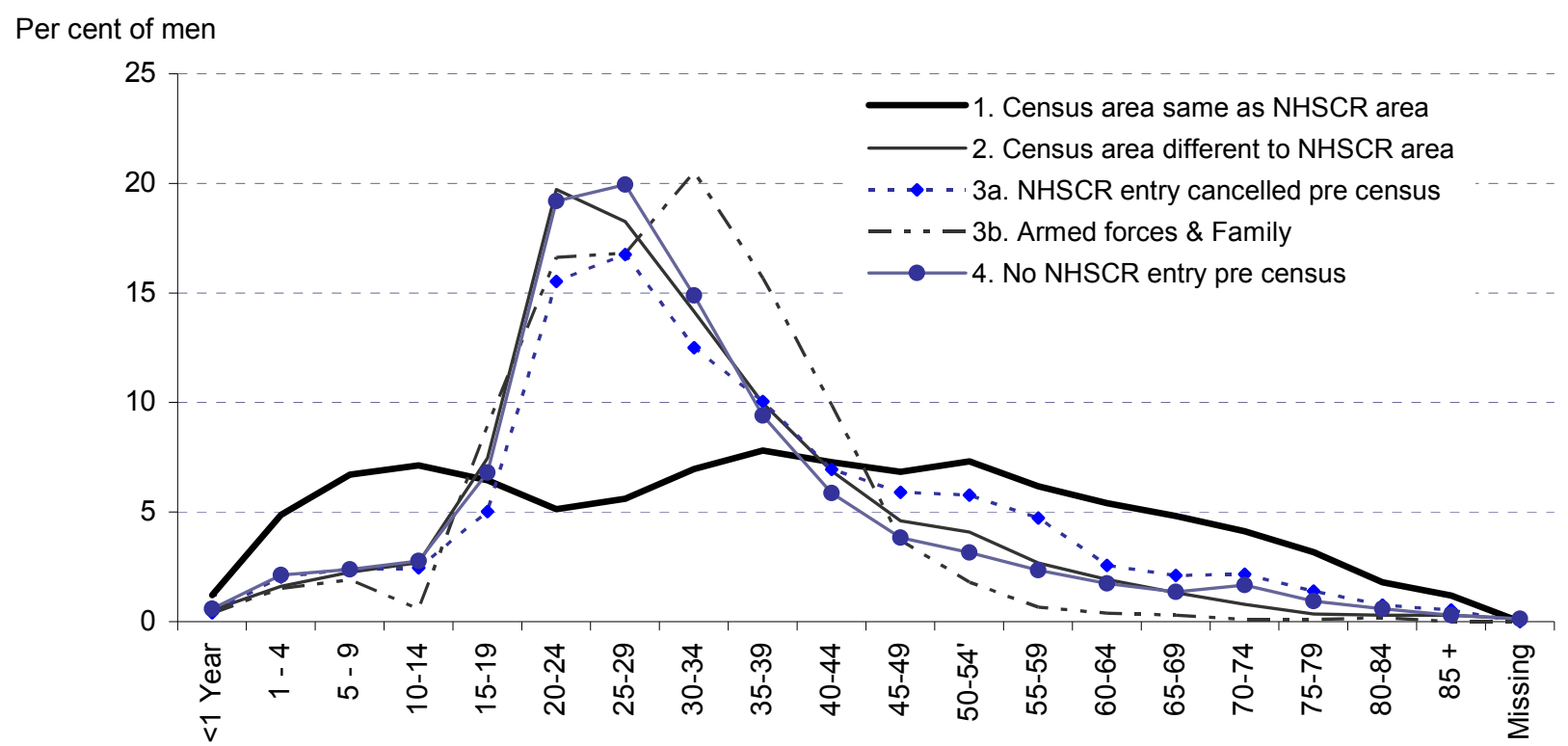

(b) Females

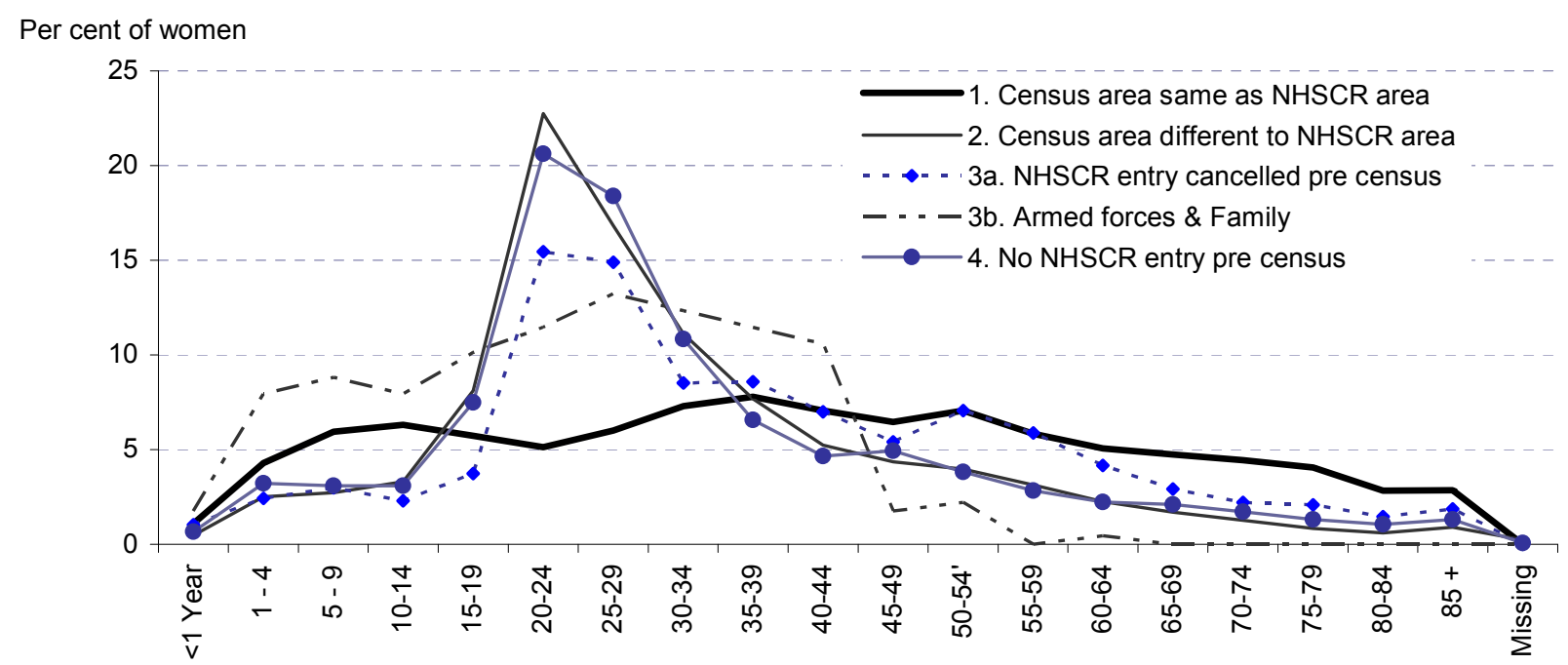




\section{Students}

A further subdivision of the data was carried out to see if there was any particular effect from those who were recorded as students in the 2001 Census. Table 8 shows that, broadly, there were similar proportions of students in the groups investigated. This is perhaps surprising given that all the groups where the 2001 Census does not give the same address as NHSCR are much younger on average.

\section{Table 8 Those present at 2001 Census by NHSCR location, and whether student or not}

\begin{tabular}{lrrrrr}
\hline & Students & $\begin{array}{r}\text { Per } \\
\text { cent }\end{array}$ & $\begin{array}{c}\text { Non- } \\
\text { students }\end{array}$ & $\begin{array}{r}\text { Per } \\
\text { cent }\end{array}$ & Total \\
\hline 1. Census area same as NHSCR area & 106,254 & 20.6 & 410,504 & 79.4 & 516,758 \\
2. Census area different to NHSCR area & 3,273 & 22.1 & 11,533 & 77.9 & 14,806 \\
3a. NHSCR record cancelled pre census & 598 & 18.9 & 2,557 & 81.1 & 3,155 \\
3b. Armed forces \& Family & 106 & 8.3 & 1,173 & 91.7 & 1,279 \\
4. No NHSCR record pre census & 907 & 23.5 & 2,960 & 76.5 & 3,867 \\
Total & $\mathbf{1 1 1 , 1 3 8}$ & $\mathbf{2 0 . 6}$ & $\mathbf{4 2 8 , 7 2 7}$ & $\mathbf{7 9 . 4}$ & $\mathbf{5 3 9 , 8 6 5}$ \\
\hline
\end{tabular}

The age distributions show that students are much younger than the non-students in each of the groups. Figure 4 shows the age distributions for students and non-students, the great majority of students being aged under 25; that students are likely to be particularly important for differences in the 20-24 age group (between ages 5 and 19 the majority of the population are students, but are also dependent children). However, it is possible that those who were ever students are affecting the higher age ranges. Further work may be possible to analyse this group using educational qualification. 


\section{Figure 4 Age distribution of different categories of those present at 2001 Census, students and non-students}

(a) Students

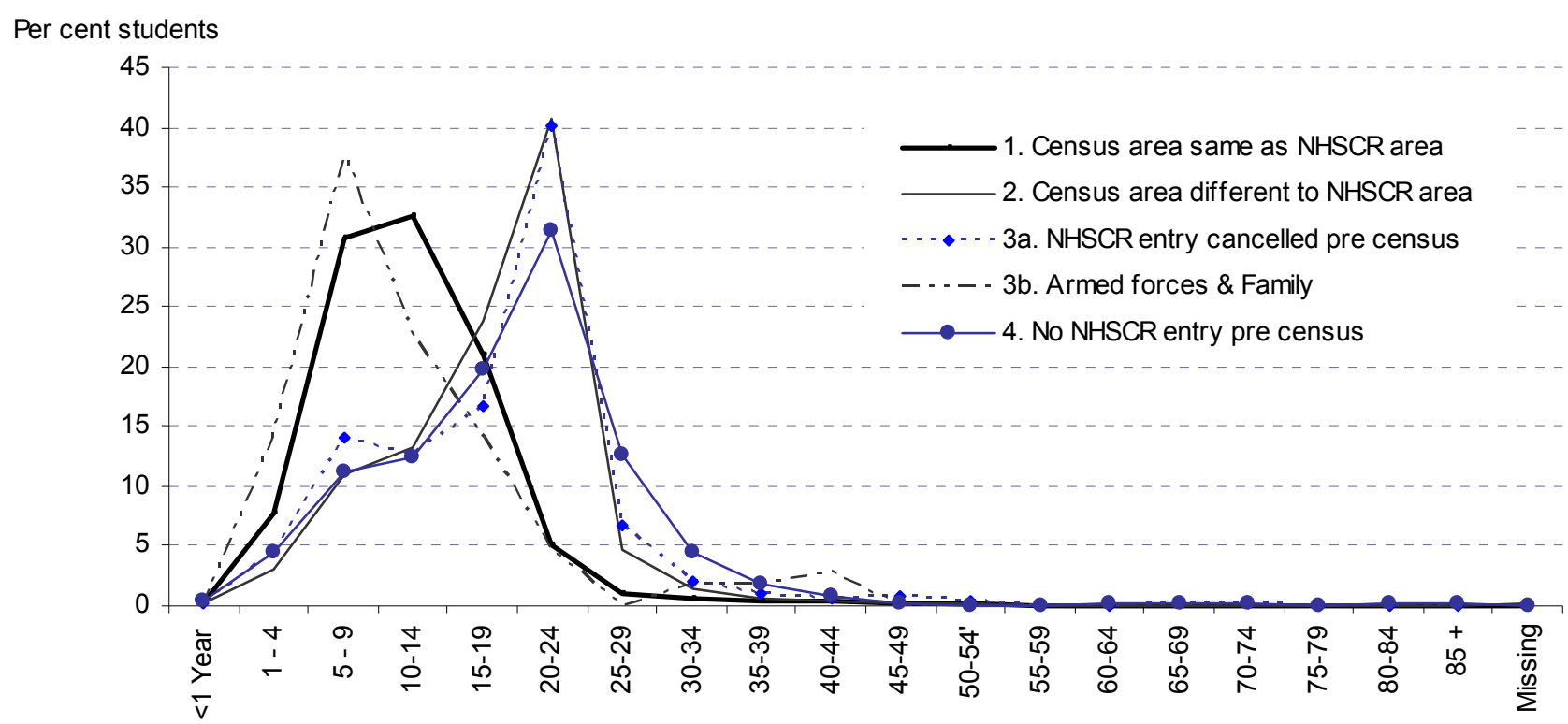

(b) Non students

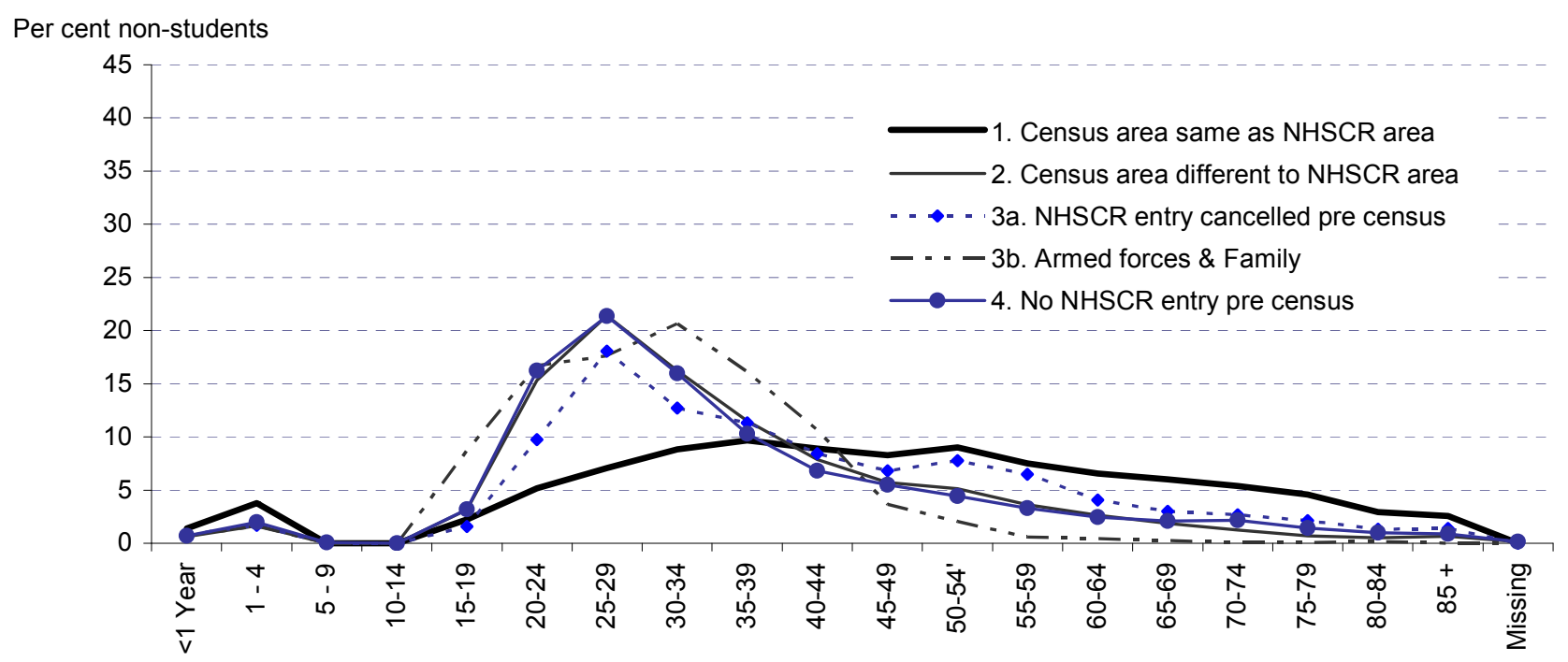

\section{Births and deaths}

The ONS Longitudinal Study also contains registrations of births and deaths. Births and deaths are used in the construction of population estimates, while those who are born or have died are added to/removed from the NHSCR. Comparisons were made only where first NHSCR entry (for births) and the last NHSCR entry prior to death was in England and Wales. For births the comparison was made between the residential address of the mother given at the registration of the birth and the first posting (health authority area of registration) of the child born, for children selected into the 
ONS LS. For deaths, the comparison was with the residential address given for the deceased at death registration, together with the final posting on the NHSCR for the death. Only 1.7 per cent of births $(564$ of 33,298$)$ and 1.9 per cent of deaths $(579$ of 30,484$)$ were found to have a different health authority area when the sources were compared; for 40 per cent of the deaths with a different area there was evidence that the person had moved within the previous calendar year: it could be hypothesised that these are moves to be closer to relatives, perhaps to live with them or into sheltered accommodation, care homes and hospices. It is reassuring that most deaths are within the same health authority area in both sources, and also that the patient register picks up these final moves. However, in the small number of cases where there is a different address and evidence of a recent move, there is an issue for population estimation. These final moves will be included in the estimation of internal migration, while the deaths will be subtracted from the previous health authority area.

\section{Length of time to recording of change}

For those who are recorded in a different place on the patient register than where they are found in the 2001 Census, but then move, it is possible to look at how long it then takes before that move is recorded on the register. The first group (category 2) are those who were subsequently recorded as having moved to their census area.

Figure $\mathbf{5}$ shows the patterns for males and females. Note that this is only those who have moved; there are more males than females enumerated in a different area at time of census, and, similarly, there are more males in the category of moving ( 4,205 males and 2,845 females). As a proportion of the total, those who have moved is similar across the sexes (46 per cent males and 48 per cent females). Within one month, one in 10 males and around one in seven females moved to their census area. Of all the women who moved, half moved by the sixth month following the census; for men this was in the tenth month. Of course, these are marginal differences in terms of calculating population estimates, but it does suggest that there is a material difference in the speed of reregistering with a GP for men compared with women.

\section{Figure 5 Length of time taken to move to place of census enumeration in NHSCR}

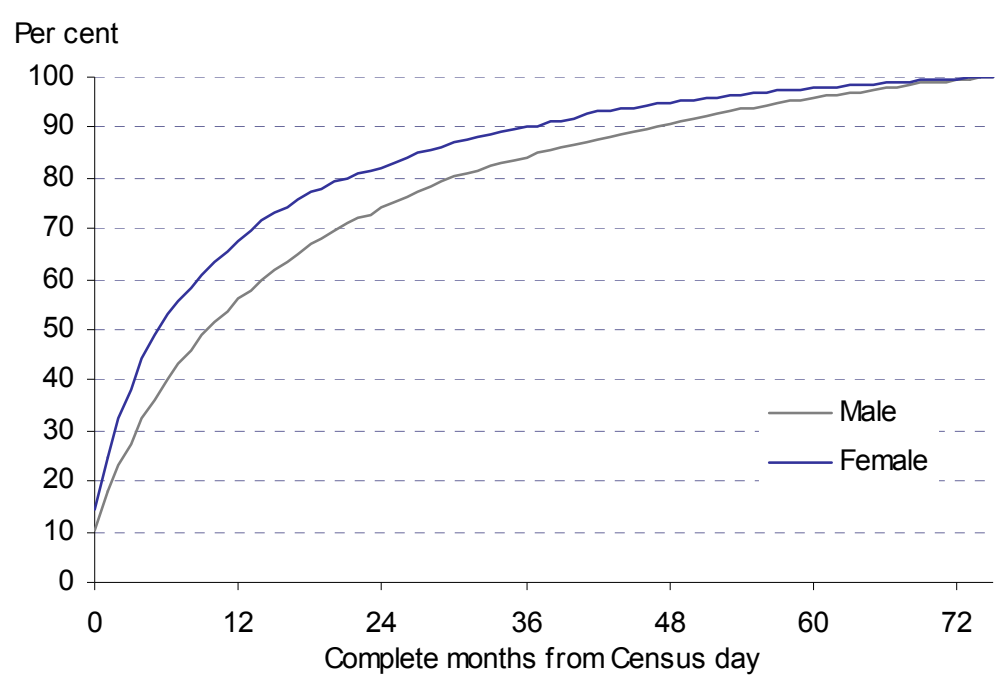


Figure 6 shows a similar analysis for those with no entry on the patient register prior to census. Only 23 per cent of men and 27 per cent of women end up with an NHSCR entry in the census area. For those who do, there is still a difference between men and women in the timing, but the differences are smaller than in figure 4 , and the movement is slightly faster.

\section{Figure 6 Length of time taken to appear at place of census enumeration where no entry on patient register at time of 2001 Census}

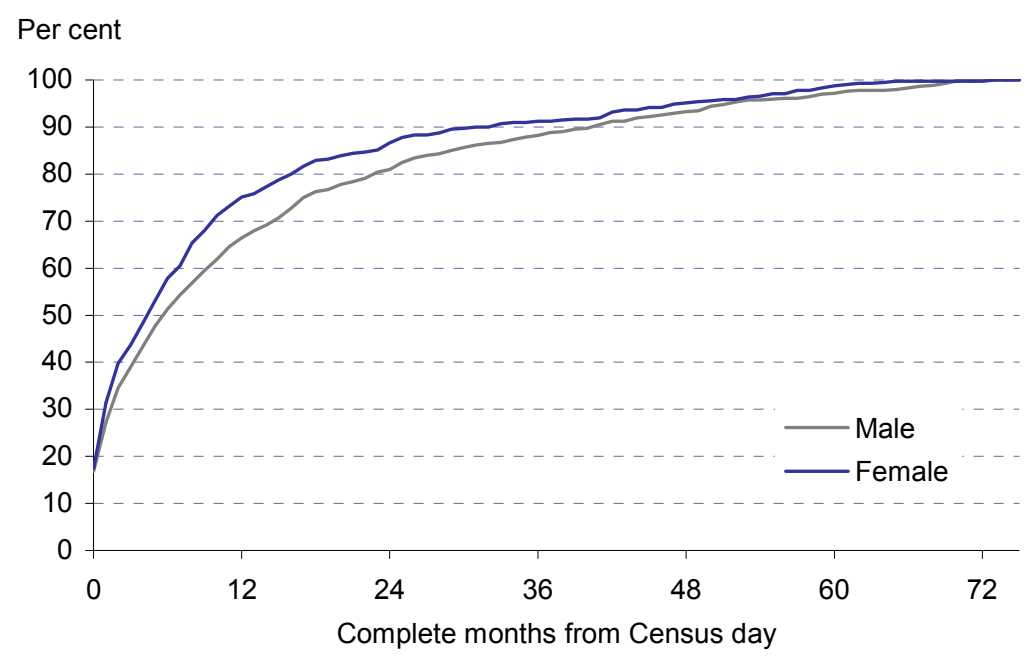

\section{Figure 7 Length of time taken to appear on patient register at place of census enumeration after census where previously cancelled on the NHSCR}

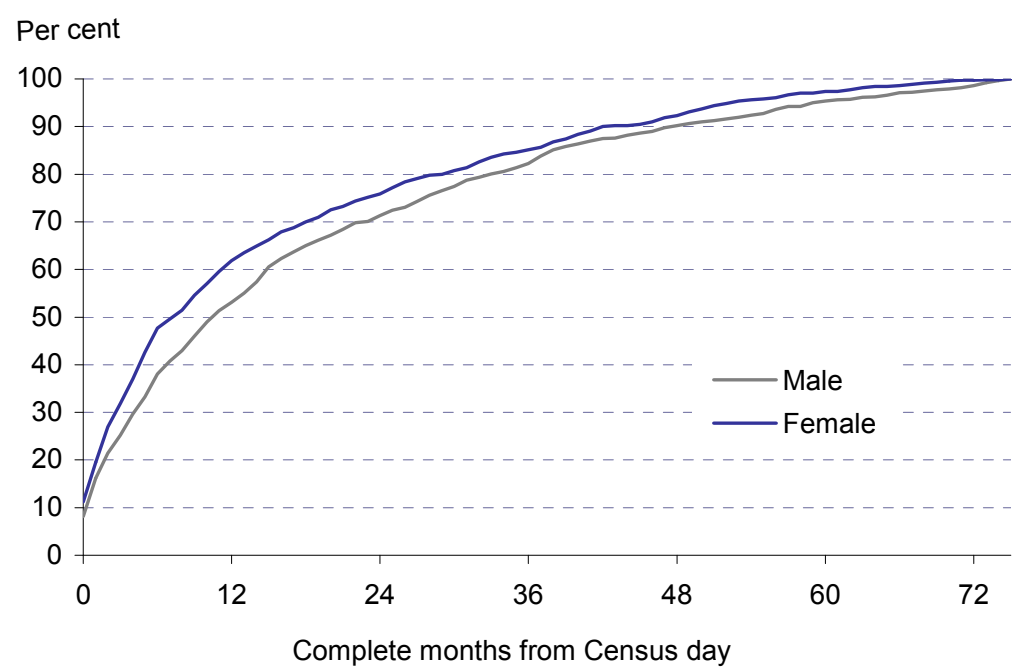

Finally, Figure 7 shows the patterns for people reappearing on the NHSCR after the census, having been cancelled on the register prior to census. Around 47 per cent of men and 49 per cent of women re-appear. Again women re-appear more quickly than men. Some caution is required 
here as this analysis does not consider how long before census the cancellation took place. Also the cancellation may have been legitimate if the person had emigrated at some point.

\section{Discussion}

This article has shown the richness of administrative data that can be produced when it is compared with census data in a longitudinal analysis. The analysis provides reassurance that, generally, the patient register is a good quality administrative source, and in most cases matches with the information collected at census. Even where there are lags in the movement of people recorded by the NHSCR the proportion is not large and there is a lot of net cancelling, at least at the GOR level. Where there are quality issues, the ONS LS is able to quantify the extent of those issues and differentiate them by age, sex and population subtype. This analysis has looked at the sub-type of students; it shows how other data sources which identify population and place, if they were included in the ONS LS, might be analysed to show their quality with regard to place. This could be particularly important as sometimes claims of deficiency are made against administrative data, often because there is insufficient incentive for users to update their address.

As patient register data is currently an input into making population estimates, which are used for resource allocation, it is important to understand their strengths and limitations. Increasingly, however, there is pressure to move away from the traditional systems of taking censuses and then creating subsequent population estimates using cohort component methods, rather than using the administrative sources themselves to produce the population estimates. Such a move gives even greater importance to understanding the quality of the administrative sources. This article points the way to how other data sources could be examined, if they could be linked into the ONS LS.

This article has not covered all the potential of analyses, possible using the ONS LS, to look at patient register data. As well as further work on students, other possible work could be a more detailed analysis of the information on migration recorded in the census from the question about the respondent's address one year ago. Examining this would assist in interpreting the timing data, since the sub-group that has moved before the census, but still have an address one year ago on the NHSCR, can be followed up to see if and when that move was recorded. A direct comparison of the moves that took place between May 2000 and May 2001 (allowing a one month lag for moves to take place) on the NHSCR could also be compared with those that identified themselves as moving internally to supplement macro comparisons already carried out ${ }^{3}$.

\section{Conclusion}

The proportion of the population that completes a census form but that never appears on the NHSCR is small (estimated at 0.5 per cent of those enumerated in 2001 Census). While there is an issue around where census counts people, and where those people currently are in the NHSCR, the issue does appear to be small. However, it may need to be considered when initially rolling forward from 2011 Census to the mid-year estimate to prevent double counting of movers.

This work provides further evidence that men are more likely to be mis-recorded in GP registers compared to women. The proportion of students is slightly higher in the groups who are registered in a different area from census or are found in census, but not on the NHSCR. The students in 
these groups are younger than the non-students. However, overall, students do not dominate the numbers in those categories where 2001 Census and NHSCR do not match.

The issues around births and deaths seem very small, being less than two per cent of the total number of events, which itself is a relatively small proportion compared to the total population.

This work essentially relates to a 'snap shot' in 2001. It cannot answer the question: are things better or worse now? In particular, since 2001, there has been a growth in numbers of international migrants; and this work does not take that growth into account. Once the 2011 Census results are linked to the ONS LS, and time has elapsed to allow for subsequent information to accrue, this work can be updated.

\section{Key findings}

- Overall, 95.7 per cent of ONS LS members enumerated at the 2001 Census resided in the same area as recorded on the NHSCR data.

- The proportion enumerated in the census that never appear in NHSCR registration is small, estimated at 0.5 per cent of those enumerated in 2001 Census.

- This work provides evidence, consistent with other analyses, that men are more likely to be mis-recorded in NHSCR registration than women.

- Where there are lags in movements in the NHSCR system there is evidence that once compensating differences are taken into account the net effect by Government Office Region is small.

- The proportion of students is only slightly higher in the groups who are at a different address from census, or are found in the 2001 Census but not on NHSCR. However, this work only identifies those that are currently students; it is unable at present to identify those who were ever a student.

- The article also compares registrations of births and deaths in the period 2001-06. Differences in geography around births and deaths look very small, being less than two per cent of the total number of events, which in themselves are a relatively small proportion when compared with the total population.

\section{Acknowledgements}

The authors wish to acknowledge the helpful comments of anonymous reviewers and the assistance of the Population Trends editorial and production team. 


\section{References}

1 Office for National Statistics (2002) 'Using Patient Registers to estimate Internal Migration Customer Guidance Notes'. Migration Statistics Unit, ONS, August 2002. Available at: www.statistics.gov.uk/statbase/EXPODATA\%5Ccommentary\%5CGuidance\%20Notes.pdf

2 Bates, AG (2004) 'Small Area Population Estimates project: data quality of administrative datasets'. Population Trends 116: 11-17.

3 Available at: www.statistics.gov.uk/downloads/theme_population/Revising_Internal_ Migration_Estimates.pdf

4 Hattersley, L and Creeser, R (1995) Longitudinal study 1971-1991: History, organisation and quality of data. Office for National Statistics Series LS7. HMSO: London.

5 www.ons.gov.uk/about/who-we-are/our-services/medical-research/about-us/national-healthservice-central-register--nhscr-/index.html

6 www.statistics.gov.uk/geography/england_health.asp

7 'Present at 2001 Census' in this context means that there is a census record linked to the LS study.

8 Those that have left England and Wales and registered with a doctor in Scotland or Northern Ireland are identified on CHRIS.

9 Blackwell, L, Lynch, K, Smith, J and Goldblatt, P (2003) Longitudinal Study 1971-2001: Completeness of Census Linkage. Series LS 10, Office for National Statistics and Centre for Longitudinal Studies, Institute of Education, University of London, London.

10 Abbott, O, Diamond, I and Jackson, N (2003) 'Key Issues in the Quality Assurance of the One Number Census'. Population Trends 113: 11-19. 